\title{
Endoscopic ultrasound appearance of dead Ascaris lumbricoides in the biliary tract
}

A 2-year-old Indian girl was referred with symptoms of biliary colic and obstructive jaundice of 3 weeks' duration. Abdominal ultrasonography revealed dilation of intrahepatic biliary radicles, a distended gallbladder, and a dilated common bile duct (CBD) of $15 \mathrm{~mm}$ (normal diameter up to $6 \mathrm{~mm}$ ) containing multiple ill-defined, oval, hyperechoic shadows near the lower end ( $\mathbf{F i g . 1}$ ). Magnetic resonance cholangiopancreatography (MRCP) showed multiple intraluminal curvilinear, hypointense areas in the lower CBD consistent with stones or worm ( $\triangleright$ Fig. 2). Linear endoscopic ultrasound (EUS) was performed for evaluation of the CBD filling defects visualized on abdominal ultrasound and MRCP. Linear EUS from the stomach and duodenal bulb revealed a dilated CBD with multiple hyperechoic structures without acoustic shadowing. EUS showed curvilinear, disc-shaped short-segment echogenic structures, 2-6mm in size, with a central anechoic core and parallel and equidistant from each other; this was suggestive of recently broken down soft parallel fragments of roundworms ( Fig.3, $>$ Video 1). The central anechoic core represented the digestive tract of Ascaris lumbricoides. Cholangiography revealed a dilated $C B D$ with tapering at the lower end showing multiple filling defects ( $>$ Fig.4). After multiple balloon sweeps on endoscopic retrograde cholangiopancreatography (ERCP), creamy white structures and yellow-colored material were removed that were suggestive of recently fragmented roundworm ( Fig.5, - Video 1). The patient's clinical condition improved significantly after ERCP, and repeat abdominal ultrasound after 1 week demonstrated decreased size of the CBD. The patient underwent deworming with albendazole, with the passage of multiple roundworms in stools further confirming the diagnosis of obstructive jaundice due to Ascaris.

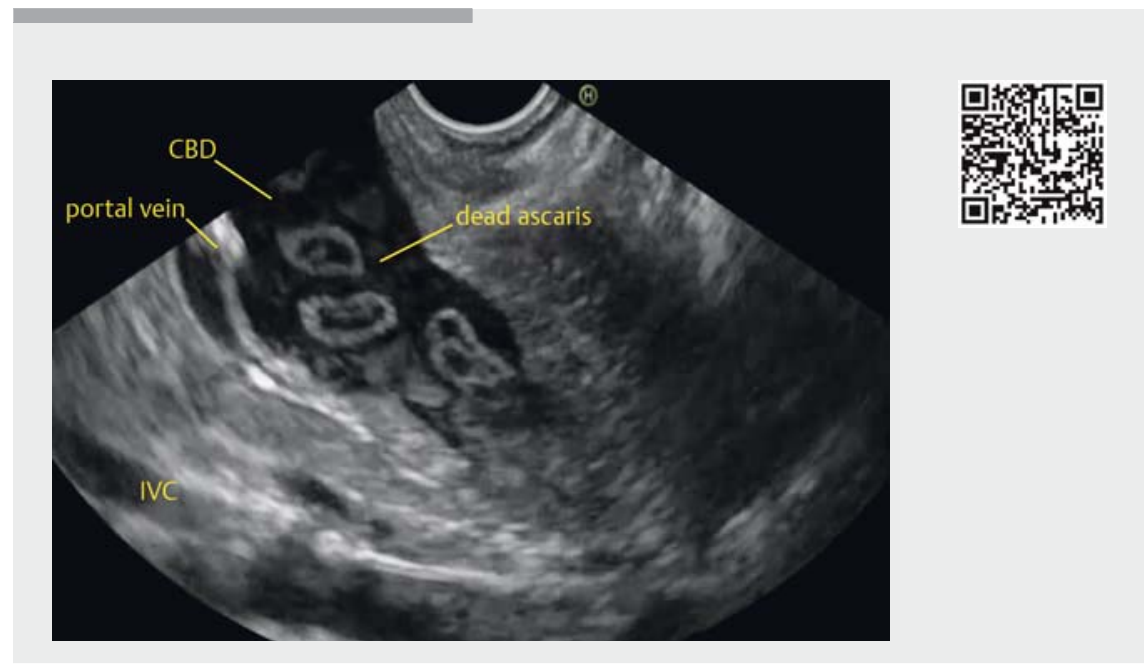

$\checkmark$ Video 1 Appearance at linear endoscopic ultrasonography (EUS) of dead Ascarislumbricoides causing obstructive jaundice in a 2-year-old girl, and removal of thefragmented roundworm at endoscopic retrograde cholangiopancreatography (ERCP). CD, cysticduct; CBD, common bile duct; IVC, inferior vena cava.

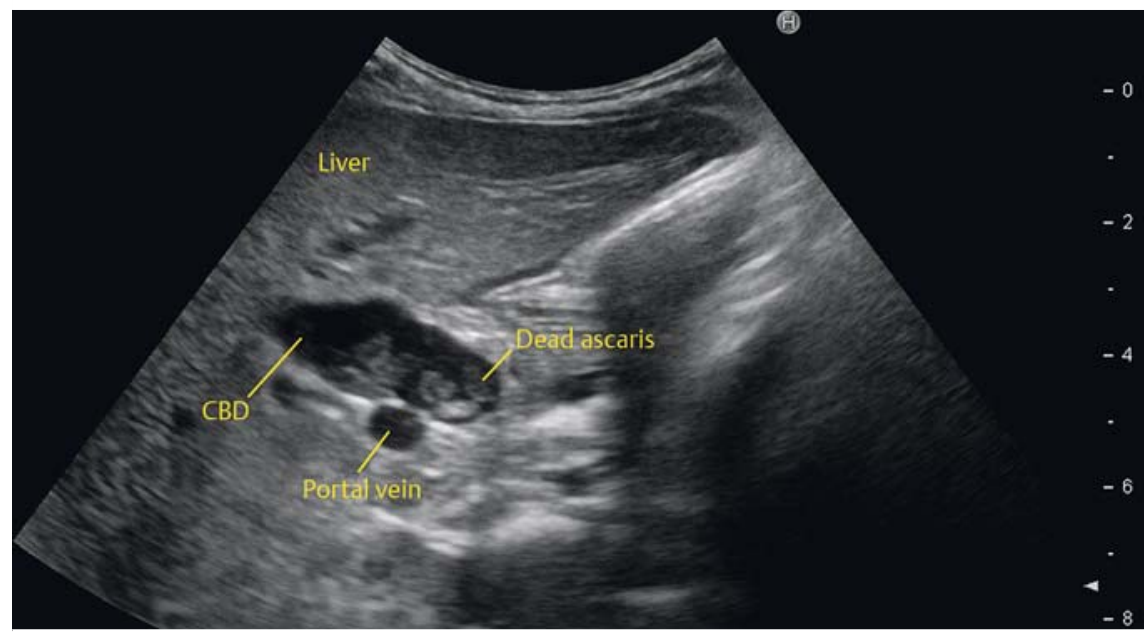

- Fig. 1 In a 2-year-old Indian girl with symptoms of biliary colic and obstructive jaundice of 3 weeks' duration, abdominal ultrasonography showed a dilated common bile duct (CBD) with multiple ill-defined, oval, hyperechoic shadows near the lower end.

Pancreaticobiliary ascariasis is a common problem in tropical countries [1]. Dead Ascaris is a rare but an important cause of obstructive jaundice in the developing world [2]. In conclusion, we describe an unusual appearance of recently dead Ascaris lumbricoides on abdominal ultra- sound, MRCP, and EUS. In endemic regions, biliary ascariasis should be considered in any child presenting with obstructive jaundice [3].

Endoscopy_UCTN_Code_CCL_1AF_2AF_3AD 


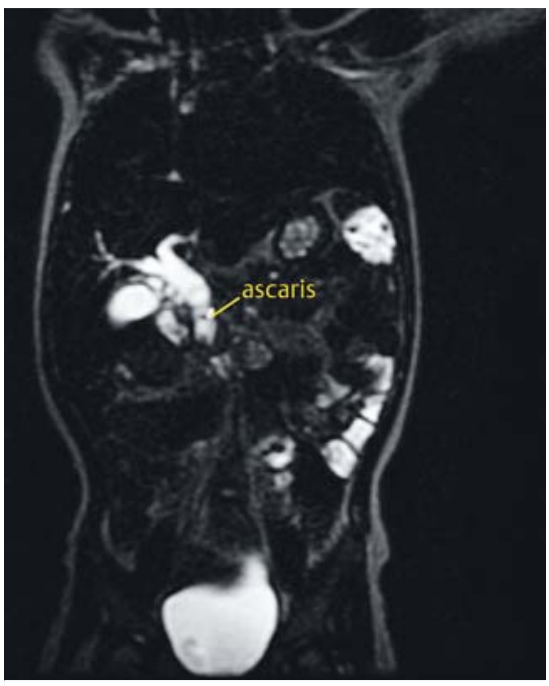

- Fig.2 Magnetic resonance cholangiopancreatography (MRCP) showed dilation of intrahepatic biliary radicles with a distended gallbladder and dilated CBD and common hepatic duct. There are multiple intraluminal curvilinear, hypointense areas in the lower CBD, consistent with stones or worm.

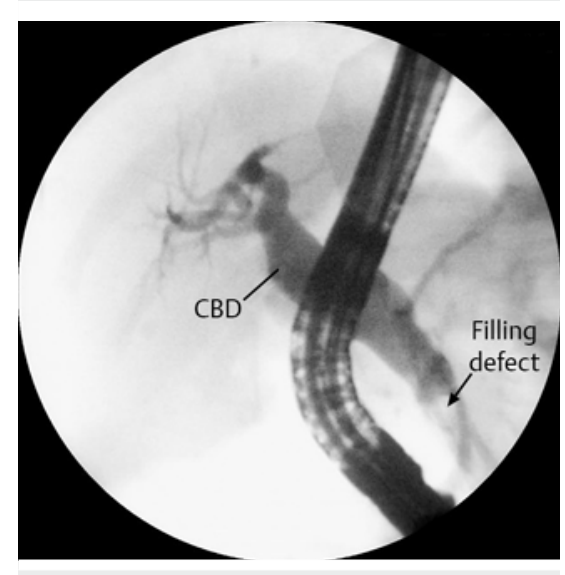

-Fig. 4 Cholangiography revealed a dilated CBD with tapering at the lower end showing multiple filling defects.

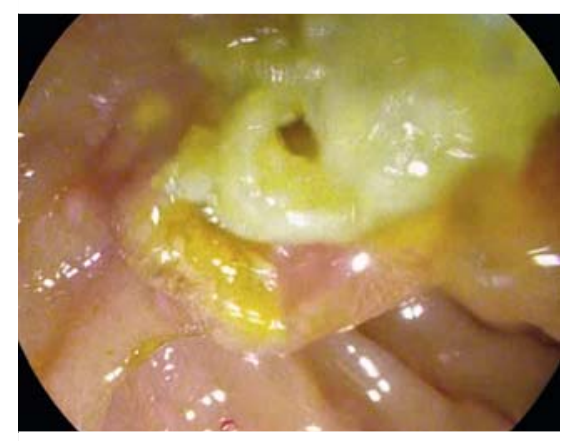

- Fig.5 At endoscopic retrograde cholangiopancreatography (ERCP) creamy white structures and yellow-colored material, suggestive of recently fragmented roundworm, were removed from the CBD.

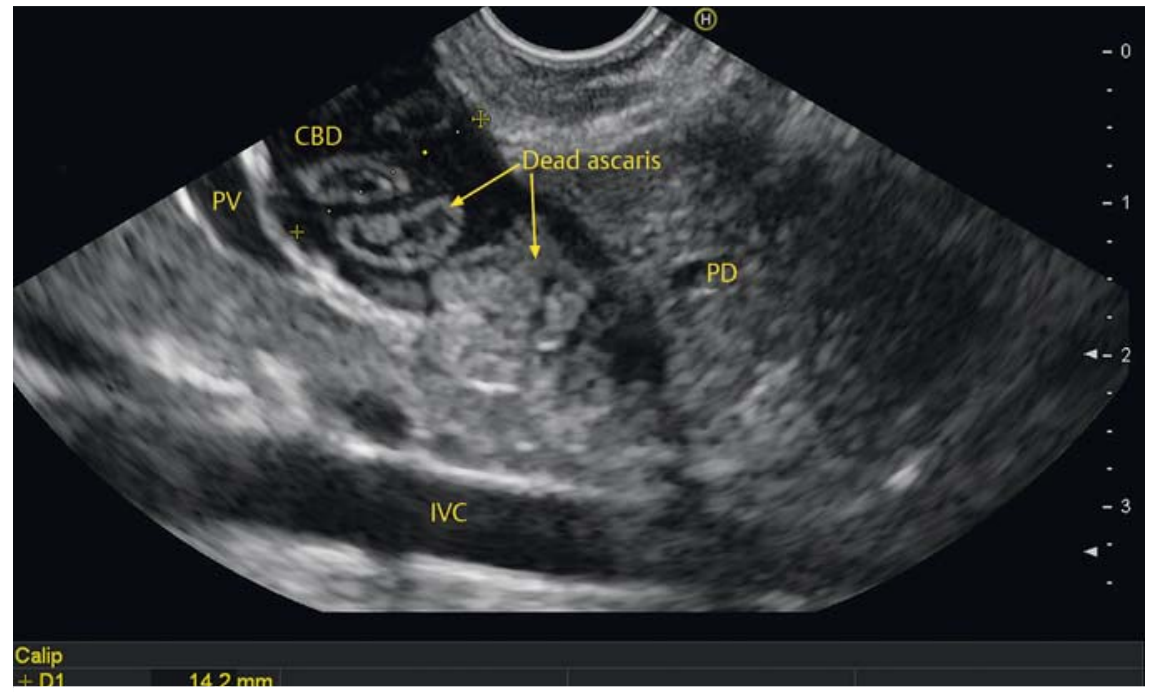

- Fig. 3 Endoscopic ultrasound (EUS) shows multiple disc-shaped echogenic structures with/ without a central anechoic core in a dilated CBD. PV, portal vein; PD, pancreatic duct; IVC, inferior vena cava.

\section{Competing interests}

All authors have no conflict of interest to disclose.

\section{The Authors}

\section{Piyush Somani, Malay Sharma, Saurabh Jindal} Department of Gastroenterology, Jaswant Rai Speciality Hospital, Saket, Meerut, Uttar Pradesh, India

\section{Corresponding author}

\section{Piyush Somani, MD, DM}

Department of Gastroenterology, Jaswant Rai Speciality Hospital, Saket, Meerut, PIN-250 001, Uttar Pradesh, India Fax: +91-121-2657154

dr_piyushsomani@yahoo.co.in

\section{References}

[1] Somani P, Sharma M, Pathak A et al. Endoscopic ultrasound imaging of pancreatic duct ascariasis. Endoscopy 2016; 48: E33E34

[2] Sharma M, Pathak A, Bansal S. Dead worm in common bile duct. Trop Gastroenterol 2011; 32: 343-345

[3] Sharma M, Mookiah B, Hari RS. Double duct sign in a 3-year-old child. Gastroenterology 2014; 146: e6-e7
Bibliography

DOI https://doi.org/10.1055/s-0043-117601

Published online: 10.8.2017

Endoscopy 2017; 49: E275-E276

(c) Georg Thieme Verlag KG

Stuttgart · New York

ISSN 0013-726X

\section{ENDOSCOPY E-VIDEOS}

https://eref.thieme.de/e-videos

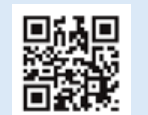

Endoscopy E-Videos is a free access online section, reporting on interesting cases and new

techniques in gastroenterological endoscopy. All papers include a high quality video and all contributions are freely accessible online.

This section has its own submission website at

https://mc.manuscriptcentral.com/e-videos 